\title{
Iranian healthcare professionals' knowledge, attitudes, and use of complementary and alternative medicine: a cross sectional study
}

\author{
Alireza Jafari ${ }^{1}$, Mohaddeseh Zanganeh ${ }^{2}$, Zahra Kazemi ${ }^{2}$, Elaheh Lael-Monfared ${ }^{3}$ and Hadi Tehrani ${ }^{4^{*}}$ (i)
}

\begin{abstract}
Background: The present study aims to investigate the knowledge, attitude, and performance of Iranian Healthcare Professionals (HP) about Complementary and Alternative Medicine (CAM) modalities.

Methods: This cross-sectional study was carried out on 210 HP in 2019. Samples were selected from healthcare centers, clinics, and hospitals using census sampling. Data collection tools included demographic information, attitude, knowledge, and the amount of use of CAM modalities. Data analysis was performed using SPSS ver. 24.

Results: In this study, the response rate was $85.3 \%$ ( $n=209)$. A majority of respondents had a positive attitude toward CAM $(n=166,79 \%)$, but their level of knowledge was limited $(n=154,73.6 \%)$. The most commonly used CAM modalities were herbal medicine (93.2\%), exercise therapy (75.4\%), and hydrotherapy (75.2\%), respectively, and the least commonly used ones were magnetic therapy (2.9\%) and hypnosis (4.8\%). The most important reasons for the use of CAM modalities by HP included fewer side effects than medical treatments (57.4\%), its lowest cost than medical treatments (34.9\%), non-serious disease with no need for referral to a clinic (32.1\%), and its more convenient access than medical treatments (30.6\%). The results showed that there was a significant relationship between the education level and the use of CAM modalities ( $p<0.05$ ). There was also a significant relationship between the suggestion of CAM modalities and the amount of use of these modalities, and those who used these modalities would also have recommended them to their clients more frequently $(p<0.05)$.

Conclusion: The results showed that most of HP used at least one of the CAM modalities and had a positive attitude towards CAM. As the level of knowledge was limited, training courses should be implemented to increase health practitioner's level of knowledge on CAM.
\end{abstract}

Keywords: CAM, Knowledge, Attitude, Behavior, Health care personnel

\section{Background}

In recent years, Complementary and Alternative Medicine (CAM) has been used more commonly, along with conventional medical treatments among patients and individuals [1-3]. CAM is defined as a group of diverse

\footnotetext{
*Correspondence: Tehranih@mums.ac.ir

${ }^{4}$ Department of Health Education and Health Promotion, Social Determinants of Health Research Center, Mashhad University of Medical Sciences, Mashhad, Iran

Full list of author information is available at the end of the article
}

medical and healthcare systems, practices, and products, which are currently not considered to be an integral part of conventional medicine [4]. Complementary medicine "refers to the therapies that complement conventional medicine (or allopathic) medicine and are used together with conventional medicine, and alternative medicine is used instead of conventional medicine". In this regard, alternative medicine "refers to those therapeutic approaches taken instead of traditional medicine and used to treat or ameliorate disease" [5]. 
In a systematic review, the rate of CAM use in the United States increased from 36\% in 2002 to $38 \%$ in 2007 [6]. In the United Kingdom about 41\% of communities and patients had used CAM last year, and $51 \%$ of them had used CAM during their lifetime [7]. About 26\% of Europeans use CAM modalities [8]. Also, the results of another study showed that the usage rate of CAM was $26.4 \%$, ranging from less than $10 \%$ in Slovenia, Poland and Bulgaria to more than 50\% in the Republic of Korea, China and the Philippines [9]. Healthcare Professionals (HP) are more likely to use CAM compared to other community members and other occupations [10]. The results of a meta-analysis showed that nurses need training courses to obtain the required information about CAM [11]. Also, the results of a study showed that physicians had more positive attitudes about CAM in 2012 than in 2004. In 2004, only $44 \%$ and in 2012 about $71 \%$ of physicians were willing to refer their patients to CAM specialists [12].

A study conducted on Iranian patients showed that 53.3\% of them used CAM, and they had insufficient information on its benefits, risks, and side effects, which could put them at risk [13]. About 95\% of Iranian patients with cancer also used at least one of the CAM modalities [14]. In addition, the results show that the use of CAM in Iranian patients has also increased from $26 \%$ in 2009 to $67 \%$ in 2015 [15, 16]. $31.3 \%$ of dermatology outpatients have used at least one of the CAM therapies [17]. In Iran about $86.6 \%$ of health care providers used CAM modalities [18]. A study on Iranian nurses showed that their knowledge of CAM is low and most of them believed that the use of CAM modalities is useful for the treatment of diseases, and they had a positive attitude towards it [19].

HP's knowledge of CAM is limited, so most of them believe that obtaining this information is essential [20, 21]. Most of Iranian nurses have a positive attitude towards the use of CAM, but they have insufficient knowledge toward CAM [22]. Also, patients often obtain information about CAM from informal sources (such as friends, family, the Internet, and the media), which may bring them wrong information and put them at risk [23-25].

HP keeps in touch with people during the first stage of prevention and can provide their clients with useful and reliable information about CAM. Since these patients may use CAM modalities to treat their disease, in addition to conventional medical treatments, HP's knowledge of the nature and effect of CAM can help in the proper use of that and also in obtaining accurate information by patients and community members. So, the aim of this study was to investigate the knowledge, attitude, and performance of healthcare professionals about CAM modalities in Iran, and whether their CAM use affected their recommendations of these modalities to patients.

\section{Methods \\ Sampling and participants}

This research was a cross sectional-analytical study conducted on HP in Torbat Heydariyeh city, Iran, from November 2018 to April 2019. The participants were selected using consensus sampling from eight health care centers, two hospitals, and two clinics. The questionnaire was distributed to all HP $(n=245)$, and 225 questionnaires were received. In this study, 15 questionnaires were excluded due to incomplete information, and 209 questionnaires were finally analyzed. Participants in this study included 8 physicians, 93 nurses, 32 midwives and 76 health workers (Fig. 1).

\section{Data collection}

The researchers distributed the questionnaire in paper form to healthcare professionals and completed it through self-reporting. After obtaining the necessary approval from the ethics committee, the research process began. For data collection, the researcher referred to healthcare centers, clinics, and hospitals. Before starting the study, the study objectives were explained to the participants and informed consent was obtained. Moreover, they assure them that their information will be kept secret from the research team. The inclusion criteria include that the person is working in the health system (including health centers, clinics, or hospitals) and is willing to participate in the study. The exclusion criterion was incomplete questionnaire information.

\section{Measures}

The content of the questionnaire is divided into four parts: demographic, CAM practice, attitude, knowledge, and use of CAM.

\section{Demographic section}

This part includes questions such as age, sex, education level, occupation, and marital status.

\section{CAM practice}

This part includes questions such as suggesting CAM modalities to clients, asking questions from clients about CAM modalities, predicting the future status of CAM modalities, the reason for using of CAM modalities, and source of information about CAM modalities (Additional file 1).

\section{Attitude section}

A standard questionnaire was used to assess the people' level of attitude about CAM modalities. This part 


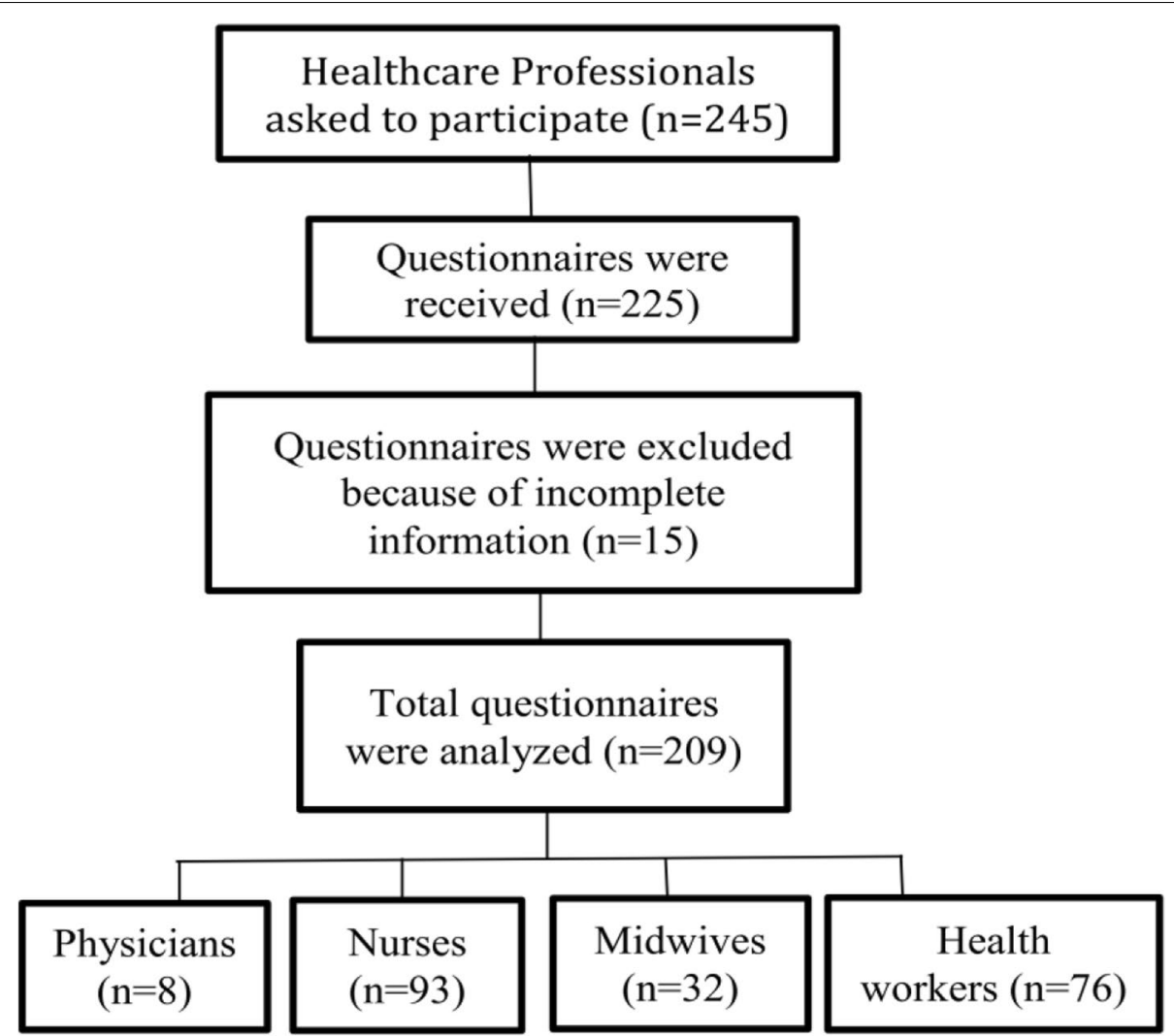

Fig. 1 Flowchart of selecting participants in this study

consists of 18 questions, which were scored using a fivepoint Likert scale (strongly agree, agree, neither agree or disagree, disagree, and strongly disagree) and assessed the individual's attitude toward CAM modalities. In this section, the lowest total score and the highest total score are 18 and 90, respectively. This section includes three subscales of health believes contains 8 questions (questions 1 to 8 , lowest score $=8$, highest score $=40$ ), the effect of CAM contains 5 questions (questions 9 to 13, lowest score $=5$, highest score $=25$ ), and risk of CAM contains 5 questions (questions 14 to 18 , lowest score $=5$, highest score $=25$ ). The Shorofi study evaluated the validity and reliability of this questionnaire and its Cronbach's alpha was 0.929 [26] (Additional file 2).

\section{Knowledge section}

A researcher-made questionnaire was used to assessment the participants' level of knowledge about 17 commonly used CAM modalities in Iran (acupuncture, music therapy, energy therapy, hypnosis, massage therapy, magnetic therapy, meditation/relaxation, yoga, therapeutic exercise, leech therapy, bloodletting, therapeutic touch, hydrotherapy, pressure therapy, vitamin supplements, herbal medicine, nutritional therapy). This section includes two subscales of mind- body practices contains 14 modalities (lowest $s c o r e=14$, highest score $=70$ ) and natural product contains 3 modalities (lowest score $=3$, highest score $=15$ ). The scoring scale of this section was used a 5-point Likert scale (low, moderate, good, very good, don't know) with a sample question: how much do you know about acupuncture? In this section, the lowest total score and the highest total score are 17 and 85, respectively (Additional file 3 ).

\section{Use of CAM section}

This section checks whether participants use the 17 CAM modalities (daily, weekly, monthly, use CAM when needed, and do not use any CAM modalities). The 17 CAM modalities were selected based on the two standard classifications adopted by the National Center for Complementary and Integrative Health (NCCIH )[27] (Additional file 4).

\section{Validity and reliability}

The face validity of the questionnaire was evaluated by providing a questionnaire to an expert panel of 9 health education experts and CAM specialists. The reliability of the questionnaire was evaluated by 10 participants ( 1 
physician, 3 nurses, 2 midwives, and 4 health care workers), and Cronbach's alpha of attitude and knowledge sections were 0.70 and 0.91 , respectively.

\section{Statistical analyses}

Data analysis was then carried out using SPSS ver. 24. To describe the data, the relevant tables, and charts, the number and percentage were used for qualitative variables, and the mean and standard deviation were used for quantitative variables. Data analysis was also carried out using of Chi-square test at significant level of less than 0.05 .

\section{Results}

\section{Socio-demographic characteristics}

The present study was carried out on $210 \mathrm{HP}$ in Iran. The response rate for this study was $85.3 \%$. The mean ( \pm standard deviation) of participants' age was 29.71 ( \pm 7.58 ) years. Of the participants, $27.4 \%$ were men, and $72.6 \%$ were women. Most participants were married (74.4\%) and had undergraduate education (71.5\%). The participants in this study included physicians (3.8\%), nurses $(45.5 \%)$, midwives $(15.3 \%)$, and health workers (36.4\%). Most of them also had less than five years of work experience. There was a significant relationship between the level of education and the participants' use of CAM $(p=0.015)$. This means that participants with a bachelor's degree used more CAM $(p=0.015)$.

\section{CAM practice}

Most of the HP (61.7\%) asked their clients about CAM, and most of them (64.2\%) had also suggested these modalities to their clients. About the future status of CAM, 67\% of participants believed that CAM will be prescribed together with conventional medical treatments (Table 1). There was also a significant relationship between the recommendation of CAM to patients and the participant's use of these modalities. Meaning that participants who used CAM also suggested these modalities to their patients $(p=0.045)$ (Table 1$)$. In this study, most HP obtained information about CAM from the internet $(65.6 \%)$, specialists $(50.7 \%)$, friends $(39.2 \%)$ and booklets $(24.4 \%)$.

\section{Attitudes toward CAM}

In this study, $79 \%(n=166)$ of the respondents had a positive attitude towards CAM. Based on the results in Table 2 , the majority of participants $(89.9 \%)$ believed that

Table 1 Demographic characteristics and their relation with the use of CAM among healthcare professionals

\begin{tabular}{|c|c|c|c|c|c|}
\hline \multirow[t]{3}{*}{ Variables } & & \multirow{3}{*}{$\begin{array}{l}\text { Data }(N=210) \\
\text { n (\%) }\end{array}$} & \multicolumn{3}{|c|}{$\begin{array}{l}\text { Use of CAM } \\
\text { (at least once during } \\
\text { lifetime) }\end{array}$} \\
\hline & & & \multirow{2}{*}{$\begin{array}{l}\text { Yes } \\
\text { n (\%) }\end{array}$} & \multirow{2}{*}{$\begin{array}{l}\text { No } \\
\text { n (\%) }\end{array}$} & \multirow[t]{2}{*}{$P$-value* } \\
\hline & & & & & \\
\hline \multirow[t]{2}{*}{ Sex } & Men & $57(27.4)$ & $55(96.5)$ & $2(3.5)$ & 0.183 \\
\hline & Women & $151(72.6)$ & $150(99.3)$ & $1(0.7)$ & \\
\hline \multirow[t]{2}{*}{ Marital status } & Marriage & $151(74.4)$ & $149(98.7)$ & $2(1.3)$ & 1 \\
\hline & Single & $52(25.6)$ & $51(98.1)$ & $1(1.9)$ & \\
\hline \multirow[t]{4}{*}{ Type of healthcare professionals } & Physicians & $8(3.8)$ & $7(87.5)$ & $1(12.5)$ & 0.036 \\
\hline & Nurses & $93(45.5)$ & $91(97.8)$ & $2(2.2)$ & \\
\hline & Midwives & $32(15.3)$ & $32(100)$ & 0 & \\
\hline & Health workers & $76(36.4)$ & $7(100)$ & 0 & \\
\hline \multirow[t]{2}{*}{ Years of practice } & $5 \geq$ & $123(61.2)$ & $121(98.4)$ & $2(1.6$ & 0.989 \\
\hline & $>5$ & $78(38.8)$ & $77(98.7)$ & $1(1.3)$ & \\
\hline \multirow{2}{*}{$\begin{array}{l}\text { Recommending complementary / alternative thera- } \\
\text { pies to your clients }\end{array}$} & Yes & $131(64.2)$ & $131(100)$ & 0 & 0.045 \\
\hline & No & $73(35.8)$ & $70(95.9)$ & $3(4.1)$ & \\
\hline \multirow{2}{*}{$\begin{array}{l}\text { Do you have any questions from your clients about } \\
\text { their use of complementary / alternative therapies? }\end{array}$} & Yes & $124(61.7)$ & $124(100)$ & 0 & 0.055 \\
\hline & No & $77(38.3)$ & $74(96.1)$ & $3(3.9)$ & \\
\hline \multirow{4}{*}{$\begin{array}{l}\text { How do you think the status of alternative therapies } \\
\text { / therapies in the future? }\end{array}$} & Replace medical treatments & $11(5.3)$ & $11(100)$ & 0 & 0.957 \\
\hline & $\begin{array}{l}\text { Both medical treatments and complemen- } \\
\text { tary therapies will be prescribed }\end{array}$ & $139(67.1)$ & $137(98.6)$ & $2(1.4)$ & \\
\hline & Only medical treatments will be prescribed & $5(2.4)$ & $5(100)$ & 0 & \\
\hline & I do not know & $52(25.1)$ & $51(98.1)$ & $1(1.9)$ & \\
\hline
\end{tabular}


Table 2 Attitude of healthcare professionals towards CAM

\begin{tabular}{|c|c|c|c|c|c|c|c|}
\hline \multirow[t]{2}{*}{ Items } & & \multicolumn{5}{|l|}{$\begin{array}{l}\text { Level of agreement } \\
\text { n (\%) }\end{array}$} & \multirow{2}{*}{$\begin{array}{l}\text { Subscales } \\
\text { Mean } \\
\text { (Standard } \\
\text { deviation) }\end{array}$} \\
\hline & & Strongly disagree & Disagree & Unsure & Agree & Strongly agree & \\
\hline \multirow{8}{*}{$\begin{array}{l}\text { Health believes/ } \\
\text { philosophical } \\
\text { view }\end{array}$} & $\begin{array}{l}\text { 1. CAM is an important aspect of my } \\
\text { own family's health care }\end{array}$ & $11(5.3)$ & $22(10.6)$ & $93(44.9)$ & $73(35.3)$ & $8(3.9)$ & \multirow[t]{8}{*}{$25.73(3.47)$} \\
\hline & $\begin{array}{l}\text { 2. Both mind and body must be treated } \\
\text { for the patient to regain complete } \\
\text { health }\end{array}$ & $3(1.4)$ & $4(1.9)$ & $14(6.7)$ & $114(54.5)$ & $74(35.4)$ & \\
\hline & $\begin{array}{l}\text { 3. Patients should have the right to } \\
\text { choose between conventional treat- } \\
\text { ments and CAM therapies in health care }\end{array}$ & $5(2.4)$ & $19(9.2)$ & $30(14.5)$ & $127(61.4)$ & $26(12.6)$ & \\
\hline & $\begin{array}{l}\text { 4. Conventional health care services are } \\
\text { too impersonal }\end{array}$ & $5(2.5)$ & $43(21.1)$ & $79(38.7)$ & $62(30.4)$ & $15(7.4)$ & \\
\hline & $\begin{array}{l}\text { 5. People are afraid of examinations and } \\
\text { treatments from conventional health } \\
\text { care services }\end{array}$ & $13(6.3)$ & 70 (33.8) & $61(29.5)$ & $57(27.5)$ & $6(2.9)$ & \\
\hline & $\begin{array}{l}\text { 6. Conventional health care services do } \\
\text { not meet people's expectations }\end{array}$ & $14(6.8)$ & $54(26.3)$ & $60(29.3)$ & $68(33.2)$ & $9(4.4)$ & \\
\hline & $\begin{array}{l}\text { 7. The changes that have taken place } \\
\text { in the conventional health care system } \\
\text { have encouraged people to use CAM } \\
\text { methods to a greater extent }\end{array}$ & $6(2.9)$ & $33(16)$ & $80(38.8)$ & $81(39.3)$ & $6(2.9)$ & \\
\hline & $\begin{array}{l}\text { 8. Patients with an untreatable condi- } \\
\text { tion should be encouraged to seek } \\
\text { CAM therapies }\end{array}$ & $6(2.9)$ & $27(13.1)$ & $76(36.9)$ & $72(35)$ & $25(12.1)$ & \\
\hline \multirow[t]{5}{*}{ Effect of CAM } & $\begin{array}{l}\text { 9. Some forms of CAM therapies are as } \\
\text { effective as conventional treatments }\end{array}$ & $5(2.4)$ & $27(13)$ & $81(39.1)$ & $83(40.1)$ & $11(5.3)$ & \multirow[t]{5}{*}{$14.91(2.01)$} \\
\hline & $\begin{array}{l}\text { 10. Surgical patients can be helped by } \\
\text { using CAM therapies }\end{array}$ & $7(3.5)$ & $19(9.5)$ & $87(43.5)$ & 77 (38.5) & $10(5)$ & \\
\hline & $\begin{array}{l}\text { 11. Some forms of CAM therapies work } \\
\text { better than conventional treatments }\end{array}$ & $6(2.9)$ & $30(14.6)$ & $89(43.2)$ & $69(33.5)$ & $12(5.8)$ & \\
\hline & $\begin{array}{l}\text { 12. Positive effects of CAM therapies are } \\
\text { in most cases due to placebo effect }\end{array}$ & $7(3.4)$ & $27(13.1)$ & $120(58.3)$ & $50(24.3)$ & $2(1)$ & \\
\hline & $\begin{array}{l}\text { 13. CAM therapies could be used as a } \\
\text { complement to the treatments used in } \\
\text { conventional health care }\end{array}$ & $4(2)$ & $25(12.2)$ & $53(25.9)$ & $100(48.8)$ & $23(11.2)$ & \\
\hline \multirow[t]{5}{*}{ Risk of CAM } & $\begin{array}{l}\text { 14. Patients are not adequately } \\
\text { informed about CAM therapies in the } \\
\text { hospital }\end{array}$ & $7(3.4)$ & $15(7.2)$ & $42(20.2)$ & $110(52.9)$ & $34(16.3)$ & \multirow[t]{5}{*}{$15.28(2.34)$} \\
\hline & 15. CAM therapies are completely safe & $9(4.3)$ & $50(24)$ & $100(48.1)$ & $36(17.3)$ & $13(6.3)$ & \\
\hline & $\begin{array}{l}\text { 16. The use of CAM therapies may } \\
\text { delay the patients' decision to contact } \\
\text { conventional health professionals }\end{array}$ & $6(2.9)$ & $13(6.3)$ & $65(31.4)$ & $117(56.5)$ & $6(2.9)$ & \\
\hline & $\begin{array}{l}\text { 17. CAM therapies may involve } \\
\text { unknown risk factors for users' health }\end{array}$ & $6(2.9)$ & $25(12.3)$ & $80(39.2)$ & $81(39.7)$ & $12(5.9)$ & \\
\hline & $\begin{array}{l}\text { 18. CAM therapies are offered just for } \\
\text { financial gain by quack health careers }\end{array}$ & $17(8.2)$ & $70(33.8)$ & $84(40.6)$ & $31(15)$ & $5(2.4)$ & \\
\hline
\end{tabular}

both body and mind must be treated to restore complete health to patients. Most of the participants (60\%) believed that CAM therapies could be used as a complement to the treatments used in conventional health care. Also, the majority of the participants (69.2\%) believed that patients did not have sufficient knowledge of CAM in the hospital, and only $3.4 \%$ of participants disagreed (Table 2).

\section{Knowledge toward CAM}

In this study, most respondents $(n=154,73.6 \%)$ had limited knowledge of CAM modalities. Based on the results, most of the HP's knowledge about CAM modalities was related to exercise therapy (51.7\%), Herbal medicine (51.7\%), vitamin supplements (51.4 $\%)$, Nutritional therapy (46.9\%), Music therapy (28.4 
\%), Bloodletting (27.6\%), Magnetic therapy (24.4\%), and Hydrotherapy (24.1\%), respectively (Table 3 ).

\section{CAM recommendation to clients}

Most of the CAM modalities suggested by HP to the patients were herbal medicine, vitamin supplements, nutrition therapy, and hydrotherapy (Table 3).

\section{Personal use of CAM}

All HP reported that they had used at least one of the modalities of mind and body practices and natural products. The most commonly used CAM modalities were herbal medicine (such as Mint, Rosemary, Ginger, Chamomile, Thyme) (93.2\%), exercise therapy (75.4\%), hydrotherapy (75.2\%), and vitamin supplements (74.8\%) (Table 4). Also, the least commonly used CAM modalities were also magnetic therapy (2.9\%), hypnosis $(4.8 \%)$, yoga $(8.3 \%)$, acupuncture $(9.2 \%)$, and leech therapy $(9.2 \%)$ (Table 4, Fig. 2).

\section{Reasons for Using CAM}

The most important reasons for HP's use of CAM were fewer side effects than medical treatments $(57.4 \%)$, its lowest cost than medical treatments (34.9\%), non-serious disease with no need for referral to a clinic (32.1\%), and its more convenient access than medical treatments (30.6\%) (Table 5).

\section{Discussion}

The aim of this study was to investigate the knowledge, attitude, and performance of healthcare professionals about CAM modalities in Iran, and whether their CAM use affected their recommendations of these modalities to patients. The results of this study showed that HP had a positive attitudes towards CAM, and most of them used CAM. Also, HP had an insufficient knowledge about CAM modalities.

\section{Personal use of CAM}

The results of the current study showed that most of the HP used at least one CAM modalities, and the most commonly used modalities were herbal medicine, exercise therapy, hydrotherapy, and vitamin supplements, respectively. The results of a study on HP in Trinidad and Tobago showed that most of the HP used CAM [20]. Moreover, a study on HP in the United States showed that about $76 \%$ of them used at least one of the CAM modalities [10]. In a study on nurses, Gyasi stated that the most commonly used modalities including nonherbal supplements, relaxation techniques, massage therapy, spirituality/prayer therapy, and music therapy, and those who obtained higher knowledge scores, used CAM modalities more frequently [23].
A systematic review study showed that the usage rate of CAM ranges from 25 to $96 \%$ in nurses. A study in Nigeria showed that the most commonly used modalities of CAM in HP were worship and prayer [28]. Also, in another study, the most commonly used modalities by HP were massage therapy, non-herbal supplements, and music therapy [27]. The variety of modalities used or the different rates of using CAM in studies may be due to the different cultural and religious or geographic regions of each community.

\section{Attitudes toward CAM}

The results of this study showed that only $21 \%$ of the participants had negative attitudes, while most of them had positive attitudes toward CAM. A systematic review study on nurses showed that most of them had positive attitudes toward the use of CAM [11]. The results of another study on HP also showed that most of them had positive attitudes toward CAM [22]. Another study conducted by Nejatian in Iran showed that health care providers had positive attitudes toward use of CAM [18]. In a study by Shorofi, about $60 \%$ of nurses had positive attitudes toward CAM [26]. The results of Aveni's study also showed that most healthcare professionals have a positive attitude towards CAM and believe that the use of CAM could be useful for the treatment of patients [29].

\section{Knowledge toward CAM}

The results of the present study show that most of the participants had inadequate level of knowledge about CAM. The first step in performing any behavior is to acquire the necessary knowledge. Lack of sufficient knowledge may endanger a people's health or others health. Low knowledge on CAM can have adverse consequences for those HP who recommend using these modalities to their clients [23]. Therefore, due to the lack of sufficient knowledge of healthcare professionals, it is necessary to provide some appropriate training courses to improve their knowledge toward CAM modalities.

The results of a study showed that, those HP who had inadequate knowledge about CAM were not sure that these modalities are useful to their clients and that they were skeptical about whether to suggest these modalities to the clients [30]. A study conducted by Gyasi in Ghana showed that nurses had limited knowledge of CAM, and only $4.5 \%$ of nurses had a high level of knowledge about CAM. Nurses also reported that they had an excellent knowledge on spirituality/ prayer therapy, massage therapy, relaxation modalities, non-herbal supplements, and music therapy [23]. In the Stub's study, most of the personnel information was related to acupuncture, massage, and mindfulness [31]. In a national study performed in Sweden, Bjerså 


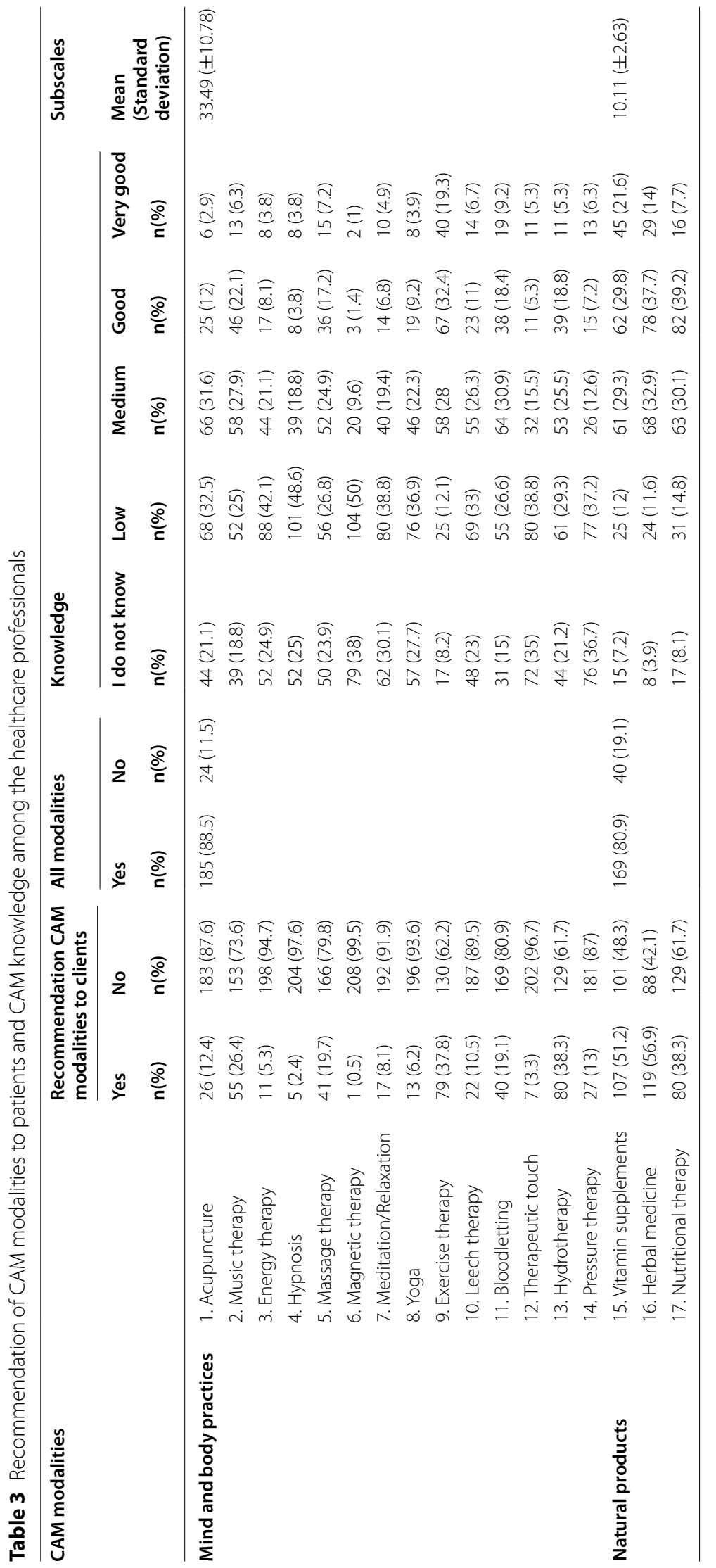


Table 4 The frequency of CAM modalities uses by healthcare professionals

\begin{tabular}{|c|c|c|c|c|c|c|}
\hline \multirow[t]{2}{*}{ CAM modalities } & & \multicolumn{5}{|l|}{$\mathrm{n}(\%)$} \\
\hline & & Daily & Weekly & Monthly & I use if necessary & I have not used it yet \\
\hline \multirow[t]{14}{*}{ Mind and body practices } & 1. Acupuncture & $1(0.5)$ & - & - & $18(8.7)$ & $188(90.8)$ \\
\hline & 2. Music therapy & $33(15.9)$ & $14(6.8)$ & $2(1)$ & $49(23.7)$ & 52.7 \\
\hline & 3. Energy therapy & $4(1.9)$ & $4(1.9)$ & $2(1)$ & $21(10.1)$ & $176(85)$ \\
\hline & 4. Hypnosis & $1(0.5)$ & - & - & $9(4.3)$ & $198(95.2)$ \\
\hline & 5. Massage therapy & $5(2.4)$ & $6(2.9)$ & $8(3.8)$ & $61(29.3)$ & $128(61.5)$ \\
\hline & 6. Magnetic therapy & - & - & $1(0.5)$ & $5(2.4)$ & $201(97.1)$ \\
\hline & 7. Meditation/Relaxation & $6(2.9)$ & $2(1)$ & $8(3.8)$ & $26(12.4)$ & $167(79.9)$ \\
\hline & 8. Yoga & - & - & $2(1)$ & $15(7.3)$ & 91.7 \\
\hline & 9. Exercise therapy & $28(13.5)$ & $40(19.3)$ & $16(7.7)$ & $72(34.8)$ & $51(24.6)$ \\
\hline & 10. Leech therapy & - & $2(1)$ & $2(1)$ & $15(7.2)$ & $188(90.8)$ \\
\hline & 11. Bloodletting & $2(1)$ & - & $3(1.4)$ & $37(17.8)$ & $166(79.8)$ \\
\hline & 12. Therapeutic touch & $2(1)$ & $5(2.4)$ & $1(0.5)$ & $18(8.7)$ & $181(87.4)$ \\
\hline & 13. Hydrotherapy & $4(1.9)$ & $8(3.8)$ & $8(3.8)$ & $50(24)$ & $138(66.3)$ \\
\hline & 14. Pressure therapy & $5(2.4)$ & $2(1)$ & $2(1)$ & $16(7.7)$ & $182(87.5)$ \\
\hline \multirow[t]{3}{*}{ Natural products } & 15. Vitamin supplements & $18(8.7)$ & $14(6.8)$ & $28(13.6)$ & $94(45.6)$ & $52(25.2)$ \\
\hline & 16. Herbal medicine & $19(9.2)$ & $16(7.7)$ & $28(13.5)$ & $130(62.8)$ & $14(6.8)$ \\
\hline & 17. Nutritional therapy & $13(6.3)$ & $10(4.9)$ & $23(11.2)$ & $95(46.1)$ & 65 (31.6) \\
\hline
\end{tabular}

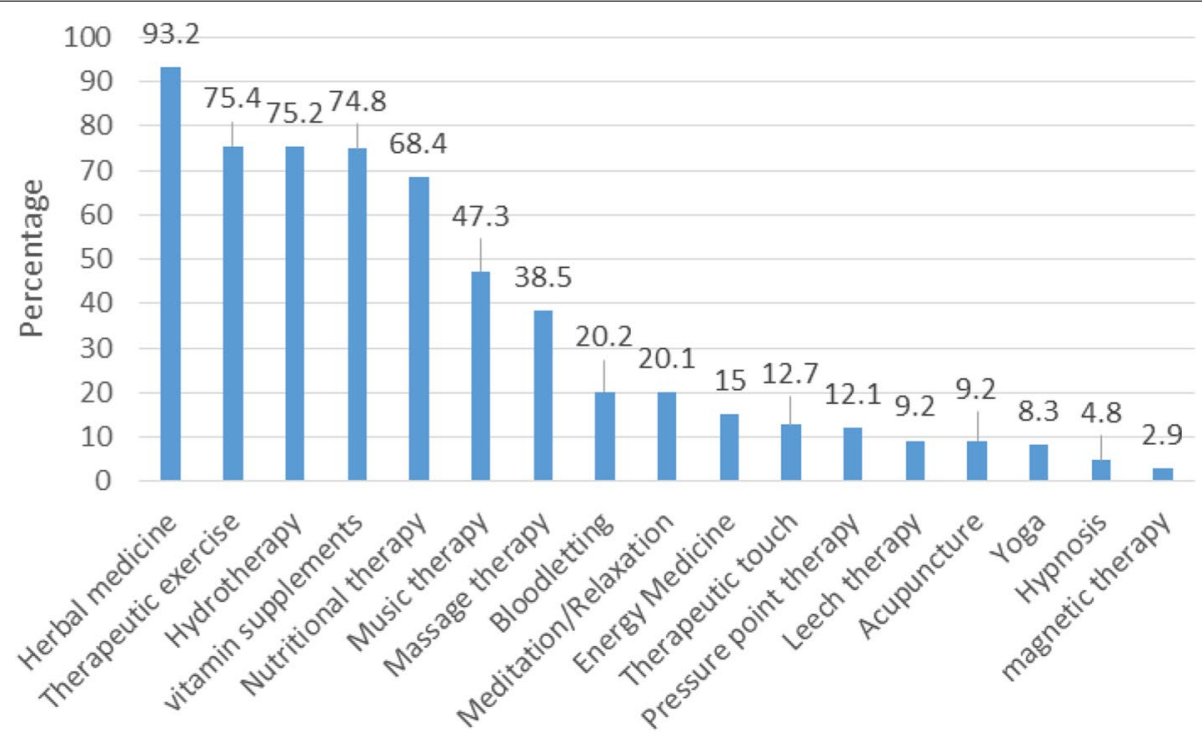

Fig. 2 CAM modalities use by healthcare professionals at least once during lifetime

showed that the majority of HP had limited knowledge on CAM (95.7\%) [21]. The results of Aveni's study on healthcare professionals showed that most of them do not sufficient knowledge on CAM, and most of them also believe that healthcare professionals should be able to inform patients about CAM [32].

\section{The source of information about CAM}

The results show that most of the HP get information on the CAM from the internet, specialists, and friends. People can access various information sources to perform their behaviors, and they can also obtain information from different sources. However, it should be pointed 
Table 5 Reasons for the use of CAM modalities by healthcare professionals

\begin{tabular}{|c|c|c|c|c|}
\hline \multirow[t]{2}{*}{ Items } & \multicolumn{2}{|l|}{ Yes } & \multicolumn{2}{|l|}{ No } \\
\hline & $\mathbf{n}$ & $\%$ & $\mathbf{n}$ & $\%$ \\
\hline 1. Its lowest cost than medical treatments & 73 & 34.9 & 136 & 65.1 \\
\hline 2. Dissatisfaction with medical treatment & 32 & 15.3 & 177 & 84.7 \\
\hline 3. Recommended by a physician & 26 & 12.4 & 183 & 87.6 \\
\hline 4. Its more convenient access than medical treatments & 64 & 30.6 & 145 & 69.4 \\
\hline 5. To strengthen the effects of the medications prescribed by a physician & 32 & 15.3 & 177 & 84.7 \\
\hline 6. Fewer side effects than medical treatments (medication Chemical) & 120 & 57.4 & 89 & 42.6 \\
\hline 7. Because it has better effectiveness than medical treatments (drugs Chemical) & 36 & 17.2 & 173 & 82.8 \\
\hline 8. To control my disease & 27 & 12.9 & 182 & 87.1 \\
\hline 9. Problem is not serious enough to go to a clinic & 67 & 32.1 & 142 & 67.9 \\
\hline 10. Advice from family or friends & 71 & 34 & 136 & 64.1 \\
\hline 11. The effectiveness has been proven to me & 62 & 29.7 & 146 & 69.9 \\
\hline 12. It will improve my health & 36 & 17.2 & 171 & 81.8 \\
\hline 13. Because it fits with my lifestyle & 48 & 23.1 & 158 & 76 \\
\hline
\end{tabular}

out that all information resources may not be reliable and people may obtain incorrect information and expose themselves to various risks. Currently, the Internet is one of the most accessible sources of information. Given that the content on the Internet is very extensive and all content is untrustworthy, it is essential that health professionals have the necessary knowledge or a reliable CAM science website. Therefore, they can finally obtain accurate information on CAM and provide appropriate information to their clients.

A systematic review study showed that HP obtained their information on CAM from professional colleagues, magazines, and the internet [11]. The results of the Stub's study showed that most medical doctors gather information about complementary cancer modalities from some guidelines [33]. A study conducted by El-Olemy in Egypt showed that HP obtained most of the information related to CAM from the media, friends and relatives [34]. A systematic review among pharmacy students showed that they refer to the media, CAM specialists, and books to obtain information about CAM [35]. Also, Cooke's study showed that about $80 \%$ of nurses obtain information about CAM through the Internet [36].

\section{Reasons for using CAM}

The most important reasons for the use of CAM by HP were fewer side effects compared to medical treatments, it's cheaper than conventional treatments. The results of the Anbari's study showed that the most important reason for using CAM is the concern about the side effects of medical treatments [37]. Based on the results of the Johnson's study conducted on HP in the United States, the main reason for the use of CAM was general health improvement [10]. Also, the Jane-lovena's study reported being natural and maintaining a healthy state as the most important reasons for using CAM [38]. There are many reasons why people often use CAM, for example, the effects of these modalities and the increase in conventional medical practice, the treatment of certain diseases, avoiding certain adverse side effects and relatively low costs [39]. People usually use CAM for various reasons, depending on the level of education, place of residence, and socioeconomic and cultural status of each individual.

\section{Asking questions about CAM from clients by HP}

In this study, most of the HP asked questions from their clients about CAM, and most of them had then suggested these modalities to their clients. Education is not a oneway process, but is considered as a two-way learning process, in which information is collected and then shared by HP to patient/client, and the patient/client makes the final decision to perform the behavior. Therefore, in the first step, HP should ask the necessary questions from their clients, and then they provide them with appropriate counseling $[30,40]$.

\section{CAM recommendation to clients}

In this study, HP noted that they more frequently suggested the use of herbal medicine, vitamin supplements, nutrition therapy, and hydrotherapy to their clients. Also, there was a significant relationship between CAM recommendations and the use of these modalities, and $\mathrm{HP}$ who uses these modalities will recommend them to their clients. Moreover, the evaluation of HP showed that they had suggested the use of massage, acupuncture, 
and pressure therapy modalities to their clients [21]. In addition, the results of the study showed that only a small number $(26 \%)$ of the personnel suggested the use of CAM to their clients [20]. In this regard, the results of a survey showed that the majority of nurses (87\%) recommend the use of at least one CAM modalities for patients [23]. Also, the results of a Hall's study showed that $50 \%$ of nurses recommend the use of CAM for surgical patients [26]. The results of the study showed that specialists who do not have sufficient knowledge of CAM doubt whether these modalities will be offered to their clients [30].

The difference in the amount of CAM suggested to clients in the other studies could be due to the different levels of attitude, knowledge, and use of CAM in HP. Given that most HP used CAM in this study and had a positive attitude toward CAM, it is predictable to recommend these modalities to their clients.

\section{Predict the state of CAM in the future}

Regarding the future use of CAM, $67 \%$ of HP believe that CAM will be prescribed along with conventional medical practices. In addition, the results of similar studies indicated that HP believes that CAM will be integrated into conventional medical practices and may be prescribed in the future $[20,41]$.

\section{Limitation}

One of the limitations of this study was that not all HP cooperated. Another limitation of this study was that the information was self-reported.

\section{Implications}

Based on the results of this study, it is it is recommended to conduct similar studies on patients and clients in health centers.

\section{Conclusion}

The results of the current study showed that the majority of HP used at least one of the CAM modalities during their lifetime. In this study, HP had a positive attitude toward CAM, while they had limited knowledge of these modalities. The results of various studies indicated that the use of CAM in patients is increasing. Therefore, it is necessary that $\mathrm{HP}$ as a reliable source for health information, take part in education courses on CAM to obtain the relevant information for providing useful counseling for clients.

\section{Abbreviations}

CAM: Complementary and Alternative Medicine; HP: Healthcare Professionals.

\section{Supplementary Information}

The online version contains supplementary material available at https://doi. org/10.1186/s12906-021-03421-z.

Additional file 1. Questionnaire of CAM practice and reason for using of CAM modalities.

Additional file 2. Questionnaire of Attitude towards CAM modalities.

Additional file 3. Questionnaire of Knowledge towards CAM modalities.

Additional file 4. Questionnaire of using of CAM modalities.

Acknowledgments

We would like to thank the Healthcare Professionals who assisted the authors in run this research project.

\section{Authors' contributions}

Authors HT, ELM and AJ designed the study. HT, AJ, ELM, ZK and MZ participated in the conception of the study. HT and AJ managed and conducted the statistical analyses and interpreted the data. AJ, ZK and MZ wrote the first draft and ELM, HT and AJ revised it to make the final manuscript. All authors have approved the final manuscript.

Funding

No financial support was received for this study.

\section{Availability of data and materials}

The data sets used and/or analyzed during the current study were available from the corresponding author on reasonable request.

\section{Declarations}

Ethics approval and consent to participate

This study is based on a research project approved by the Student Research Committee of TorbatHeydariyeh University of Medical Sciences with the code of ethics IR.THUMS.REC.1396.43. Before the study, the written informed consent obtained from all participants. All procedures performed in this study were in accordance with the ethical standards of the institutional and/or national research committee and with the 1964 Helsinki declaration and its later amendments or comparable ethical standards.

\section{Consent for publication}

Not applicable

\section{Competing interests}

The authors have no conflicts of interest

\section{Author details}

${ }^{1}$ Department of Health Education and Health Promotion, School of Health, Social Development and Health Promotion Research Center, Gonabad University of Medical Sciences, Gonabad, Iran. ${ }^{2}$ Student Research Committee, Torbat Heydariyeh University of Medical Sciences, Torbat Heydariyeh, Iran. ${ }^{3}$ Student Research Committee, School of Public Health and Safety, Shahid Beheshti University of Medical Sciences, Tehran, Iran. ${ }^{4}$ Department of Health Education and Health Promotion, Social Determinants of Health Research Center, Mashhad University of Medical Sciences, Mashhad, Iran.

Received: 24 June 2020 Accepted: 22 September 2021

Published online: 30 September 2021

References

1. Frass M, Strassl RP, Friehs H, Müllner M, Kundi M, Kaye AD. Use and acceptance of complementary and alternative medicine among the general 
population and medical personnel: a systematic review. Ochsner J. 2012;12(1):45-56.

2. McFadden KL, Hernández TD, Ito TA. Attitudes toward complementary and alternative medicine influence its use. Explore J Sci Heal. 2010;6(6):380-8.

3. Stub T, Quandt SA, Arcury TA, Sandberg JC, Kristoffersen AE. Complementary and conventional providers in cancer care: experience of communication with patients and steps to improve communication with other providers. BMC Complement Altern Med. 2017;17(1):301.

4. Abbott RB, Hui K-K, Hays RD. Mandel J, Goldstein M, Winegarden B, Glaser D, Brunton L. Medical student attitudes toward complementary, alternative and integrative medicine. Evid Based Complement Alternat Med. 2011:2011:985243.

5. Tabish SA. Complementary and alternative healthcare: is it evidencebased? Int J Health Sci. 2008;2(1):V-IX.

6. Harris PE, Cooper KL, Relton C, Thomas KJ. Prevalence of complementary and alternative medicine (CAM) use by the general population: a systematic review and update. Int J Clin Pract. 2012;66(10):924-39.

7. Posadzki P, Watson LK, Alotaibi A, Ernst E. Prevalence of use of complementary and alternative medicine (CAM) by patients/consumers in the UK: systematic review of surveys. Clin Med. 2013;13(2):126-31.

8. Kemppainen LM, Kemppainen TT, Reippainen JA, Salmenniemi ST, Vuolanto PH. Use of complementary and alternative medicine in Europe: health-related and sociodemographic determinants. Scand J Public Health. 2018;46(4):448-55.

9. Peltzer K, Pengpid S. Prevalence and determinants of traditional, complementary and alternative medicine provider use among adults from 32 countries. Chin J Integr Med. 2018;24(8):584-90.

10. Johnson PJ, Ward A, Knutson L, Sendelbach S. Personal use of complementary and alternative medicine (CAM) by US health care workers. Health Serv Res. 2012;47(1 pt1):211-27.

11. Balouchi A, Mahmoudirad G, Hastings-Tolsma M, Shorofi SA, Shahdadi H, Abdollahimohammad A. Knowledge, attitude and use of complementary and alternative medicine among nurses: A systematic review. Complement Ther Clin Pract. 2018:31:146-57.

12. Wahner-Roedler DL, Lee MC, Chon TY, Cha SS, Loehrer LL, Bauer BA. Physicians' attitudes toward complementary and alternative medicine and their knowledge of specific therapies: 8-year follow-up at an academic medical center. Complement Ther Clin Pract. 2014;20(1):54-60.

13. Behnood-Rod A, Khoshkbejari MAP, Pourzargar P, Hassanzadeh M Moharamzad Y, Foroughi F. Complementary and alternative medicine use among Iranian patients attending urban outpatient general practices. Complement Ther Clin Pract. 2018;30:58-63.

14. Amirmoezi F, Araghizadeh M, Mohebbinia Z, Kamfiroozi R, Haghpanah S, Bordbar M. Use of complementary and alternative medicine among iranian cancer patients in south of Iran. Int J Cancer Manage. 2017;10(10):e7233.

15. Ghaedi F, Dehghan M, Salari M, Sheikhrabori A. Complementary and alternative medicines: usage and its determinant factors among outpatients in Southeast of Iran. J Evid Based Complement Altern Med. 2017:22(2):210-5

16. Sajadian K, Moradi M, Mehrgan M, Tahere M. Complementary medicine use among cancer patients after excluding the praying as a complementary therapy. Iran Q J Breast Dis. 2009;2(1):13-22.

17. Dastgheib L, Farahangiz S, Adelpour Z, Salehi A. The prevalence of complementary and alternative medicine use among dermatology outpatients in Shiraz, Iran. J Evid Based Complement Altern Med. 2017;22(4):731-5.

18. Nejatian M, Alami A, Tehrani H, Lael-Monfared E, Jafari A. Perceptions and personal use of Complementary and Alternative Medicine (CAM) by Iranian health care providers. Complement Ther Clin Pract. 2018;32:145-50.

19. Zeighami M, Soltani-Nejad S. Knowledge, attitude, and practice of complementary and alternative medicine: a survey of Iranian nurses. J Res Nurs. 2020;25(4):380-8.

20. Bahall M, Legall G. Knowledge, attitudes, and practices among health care providers regarding complementary and alternative medicine in Trinidad and Tobago. BMC Complement Altern Med. 2017;17(1):144.

21. Bjerså K, Victorin ES, Olsén MF. Knowledge about complementary, alternative and integrative medicine (CAM) among registered health care providers in Swedish surgical care: a national survey among university hospitals. BMC Complement Altern Med. 2012;12(1):42.
22. Balouchi A, Rahnama M, Hastings-Tolsma M, Shoja MM, Bolaydehyi E. Knowledge, attitude and use of complementary and integrative health strategies: a preliminary survey of Iranian nurses. J Integr Med. 2016;14(2):121-7

23. Gyasi RM, Abass K, Adu-Gyamfi S, Accam BT. Nurses'knowledge, clinical practice and attitude towards unconventional medicine: implications for intercultural healthcare. Complement Ther Clin Pract. 2017;29:1-8.

24. Hall HR, Jolly K. Women's use of complementary and alternative medicines during pregnancy: a cross-sectional study. Midwifery. 2014;30(5):499-505

25. Hwang JH, Kim Y-R, Ahmed M, Choi S, Al-Hammadi NQ, Widad NM, et al. Use of complementary and alternative medicine in pregnancy: a cross-sectional survey on Iraqi women. BMC Complement Altern Med. 2016;16(1):191

26. Shorofi SA, Arbon P. Nurses'knowledge, attitudes, and professional use of complementary and alternative medicine (CAM): a survey at five metropolitan hospitals in Adelaide. Complement Ther Clin Pract. 2010;16(4):229-34.

27. Complementary, alternative, or integrative health: what's in a name? [https://nccih.nih.gov/health/integrative-health\#hed4]

28. Tor-Anyiin A, Okonkwo R, Tor-Anyiin I. Prevalence and predictors of complementary and alternative medicine (CAM) use among health workers in Nigeria. Global J Health Sci. 2018;10(12):40-51.

29. Aveni E, Bauer B, Ramelet A, Kottelat Y, Decosterd I, Finti G, et al. The attitudes of physicians, nurses, physical therapists, and midwives toward complementary medicine for chronic pain: a survey at an Academic Hospital. Explore (New York, NY). 2016;12(5):341-6.

30. Hall H, Leach M, Brosnan C, Collins M. Nurses'attitudes towards complementary therapies: a systematic review and meta-synthesis. Int J Nurs Stud. 2017:69:47-56.

31. Stub T, Quandt SA, Arcury TA, Sandberg JC, Kristoffersen AE. Attitudes and knowledge about direct and indirect risks among conventional and complementary health care providers in cancer care. BMC Complement Altern Med. 2018;18(1):44.

32. Aveni E, Bauer B, Ramelet AS, Decosterd I, Ballabeni P, Bonvin E, et al. Healthcare professionals' sources of knowledge of complementary medicine in an academic center. PLoS One. 2017;12(9):e0184979.

33. Stub T, Quandt SA, Arcury TA, Sandberg JC, Kristoffersen AE. Conventional and complementary cancer treatments: where do conventional and complementary providers seek information about these modalities? BMC Health Serv Res. 2018;18(1):854.

34. El-Olemy AT, Radwan NM, Dawood W, Abu Ali I, Fouda LM. Complementary and alternative medicine use among health workers in Mid-Delta, Egypt. Majmaah J Health Sci. 2013;1:2.

35. James PB, Bah AJ. Awareness, use, attitude and perceived need for complementary and alternative medicine (CAM) education among undergraduate pharmacy students in Sierra Leone: a descriptive cross-sectional survey. BMC Complement Altern Med. 2014;14(1):438.

36. Cooke M, Mitchell M, Tiralongo E, Murfield J. Complementary and alternative medicine and critical care nurses: a survey of knowledge and practices in Australia. Aust Crit Care. 2012;25(4):213-23.

37. Anbari K, Gholami M. Evaluation of trends in the use of complementary and alternative medicine in health centers in Khorramabad (West of Iran) Global J Health Sci. 2016;8(2):72.

38. Jane-lovena EO, Okoronkwo IL, Ogbonnaya NP. Complementary and alternative medicine use among adults in Enugu, Nigeria. BMC Complement Altern Med. 2011:11(1):19.

39. Liu MA, Huynh N-T, Broukhim M, Cheung DH, Schuster TL, Najm W. Determining the attitudes and use of complementary, alternative, and integrative medicine among undergraduates. J Altern Complement Med. 2014;20(9):718-26.

40. Bertrand SW. Inroads to integrative health care: registered nurses' personal use of traditional Chinese medicine affects professional identity and nursing practice. Complement Health Pract Rev. 2010;15(1):14-30.

41. Dobos $G$. Integrative medicine-medicine of the future or 'old wine in new skins'? Eur J Integr Med. 2009:1 (3):109-15.

\section{Publisher's Note}

Springer Nature remains neutral with regard to jurisdictional claims in published maps and institutional affiliations. 